\title{
Synthesis, Characterization and Antioxidant Activity of Carvacrol Containing Novel Thiadiazole and Oxadiazole Moieties
}

\author{
Suresh DB, Jamatsing DR, Pravin SK and Ratnamala SB* \\ School of Chemical Sciences, North Maharashtra University, Jalgaon, Maharashtra, India
}

\begin{abstract}
Carvacrol is a well-known antioxidant found in the extract of various angiospermic plants. The purpose of present research is to synthesize new carvacrol derivatives associated with heterocycles namely 1,3,4-thiadiazole and 1,3,4-oxadiazole to explore their extraordinary potential in medicine and agriculture. Structures of newly synthesized compounds were confirmed by spectroscopic techniques such as FT-IR, ${ }^{1} \mathrm{H}$ and ${ }^{13} \mathrm{C}$ NMR and LC-MS. Finally, synthesized derivatives were evaluated for their in-vitro antioxidant activity by using radical scavenger DPPH assay. All the compounds exhibited remarkable antioxidant activity, out of which compound showed better or similar antioxidant activity compared to standard compound ascorbic acid.
\end{abstract}

Keywords: Carvacrol; 1,3,4-thiadiazole; 1,3,4-oxadiazole; Antioxidant; DPPH; Ascorbic acid

\section{Introduction}

Several Reactive Oxygen Species (ROS) are important cellular components, enzymatically generated in aerobic living organisms, which show significant role in various physiological and pathological processes [1,2]. In contrast, the accumulation of excessive ROS, mostly due to external influences such as radiation, cigarette smoke, ultraviolet light, drugs, pathogens, etc can cause damage upon cellular macromolecules like, DNA, proteins and lipids, therefore contributing to the development of various diseases such as, atherosclerosis, myocardial infarction, ischemia, epilepsy, diabetes mellitus, anemia and carcinogenesis [3-5]. To overcome this, investigates aimed at the synthesis of new antioxidants with better properties from a pharmacological point of view have been performed [6] have synthesized of 1,3,4-oxadiazoles containing 4-(methyl sulfonyl) benzyl moiety and evaluated their in-vitro antioxidant activity [7]. Similarly, have reported that 1,3,4-oxadiazole tagged thieno [2,3-d] pyrimidine derivatives having significant radical scavenger activity [8].

The prevalent existence of the heterocycles in bioactive natural products, drugs, and agrochemicals has made them as important synthetic targets [9]. Five-membered heterocyclic compounds; oxadiazoles and thiadiazoles have attracted significant interest in medicinal chemistry, pesticide chemistry, polymer sciences, material science and they are the building blocks of new molecular systems for biologically active molecules [10]. The Nitrogen-oxygen heterocycles are also of synthetic interest as they constitute an important class of natural and non-natural products and many of them exhibit useful biological activities [11,12]. 1,3,4-oxadiazoles are biologically versatile compounds displaying a variety of biological effects which include antifungal [13], bactericidal [14], analgesic and anti-inflammatory [15]. 1,3,4-thiadiazoles also possess various biological properties such as antitumor, anticonvulsant, antihypertensive, anesthetic, antibacterial and cardiotonic activities [16-18]. Carvacrol (5-isopropyl3-methylphenol) is a major constituent of oregano oil [19]. Likewise, the phenolic monoterpenoids found in essential oils of many plants also possess different biological activities [20,21]. Therefore, we choose carvacrol as starting material for our research. Keeping in view the importance of oxadiazole and Thiadiazole in biology, and in continuation of our ongoing research on biologically active molecules, we have prepared oxadiazole and thiadiazole derivatives of naturally occurring phenolic antioxidant [22,23]. In this regard, it is important to search for and synthesize new classes of compounds that have antioxidant properties.

\section{Experimental}

Melting points of all the synthesized compounds were determined by open capillary method. The reaction was monitored by ascending thin layer chromatography (TLC) and was performed on $200 \mu \mathrm{m}$ thick aluminum sheets having silica gel $60 \mathrm{~F}_{254}$ as adsorbent. The solvent system used for developing the TLC plate was hexane and ethyl acetate (3:1). Spots were visualized under UV-light. ${ }^{1} \mathrm{H}$ nuclear magnetic resonance $\left({ }^{1} \mathrm{H}\right.$ NMR) and ${ }^{13} \mathrm{C}$ NMR spectra were scanned at $400 \mathrm{MHz}$ and $100 \mathrm{MHz}$ respectively on Varian Mercury YH-300 FT NMR in DMSO- $\mathrm{d}_{6}$. Chemical shift values $(\delta)$ are given in parts per million (ppm).

The antioxidant activity of the synthesized compounds was performed by 2,2-diphenyl-1-picrylhydrazyl (DPPH) free radical scavenging assay [24]. All the well characterized derivatives of carvacrol were dissolved to prepare a stock solution of $1 \mathrm{mg} / \mathrm{mL}$ using DMSO. Fifty microliter solutions of the compounds were added to $1 \mathrm{~mL}$ of a 0.1 $\mathrm{mM}$ solution of DPPH in methanol. After $2 \mathrm{~h}$, absorbance values were measured at $517 \mathrm{~nm}$. Ascorbic acid was used as standard.

\section{Synthesis}

The synthesis of the compounds was carried out according to the procedure outlined in Scheme 1. Firstly, carvacrol (Figure 1) was converted to its 4-nitroso derivatives (Supplementary Figures 1 and 2) by treating ethanolic solution of phenol with concentrated hydrochloric acid and sodium nitrite at $0^{\circ} \mathrm{C}[25]$. The nitroso compound was reduced in an ammonical solution by passing $\mathrm{H}_{2} \mathrm{~S}$ gas [26]. The 4-aminophenol (Supplementary Figure 3) prepared according to Scheme 1 was further reacted with acetic anhydride to form acetamide (Supplementary Figure 4) derivative [27]. Acetamide was treated with ethyl-bromoacetate to obtain ester type compound (Supplementary Figure 5) [28] and further converted to their hydrazide compound (Supplementary Figure 6) by reported methods [29].

*Corresponding author: Ratnamala S Bendre, School of Chemical Sciences North Maharashtra University, Jalgaon, Maharashtra, India, Tel: +91942221143; E-mail: bendrers@gmail.com

Received November 16, 2016; Accepted November 21, 2016; Published November 28, 2016

Citation: Suresh DB, Jamatsing DR, Pravin SK, Ratnamala SB (2016) Synthesis, Characterization and Antioxidant Activity of Carvacrol Containing Novel Thiadiazole and Oxadiazole Moieties. Mod Chem Appl 4: 193. doi: 10.4172/2329-6798.1000193

Copyright: (c) 2016 Suresh DB, et al. This is an open-access article distributed under the terms of the Creative Commons Attribution License, which permits unrestricted use, distribution, and reproduction in any medium, provided the original author and source are credited. 
<smiles>Cc1ccc(C(C)C)cc1ON=O</smiles>

[1]<smiles>Cc1cc([N+](=O)[O-])c(C(C)C)cc1O</smiles>

[2]<smiles>Cc1cc(N)c(C(C)C)cc1O</smiles><smiles>[14CH3][Mg][Mg]</smiles><smiles>CCOC(=O)COc1cc(C(C)(C)C)c(NC(C)=O)cc1C</smiles><smiles>CCOC(=O)CBr</smiles>
refl. 4 hrs.<smiles>CC(=O)Nc1cc(C)c(O)cc1C(C)C</smiles>

[4] $\mathrm{NH}_{2} \mathrm{NH}_{2} \cdot \mathrm{H}_{2} \mathrm{O} / \mathrm{EtOH}$

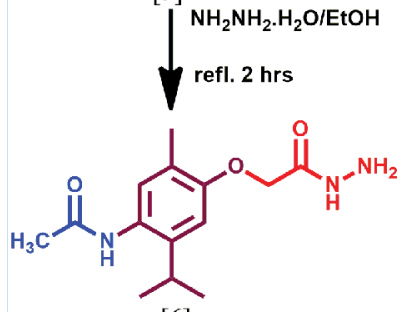

[6]<smiles>CC(=O)Nc1cc(C)c(OCC(=O)NNC(=S)S[Na])cc1C(C)C</smiles>

[7]<smiles>CC([N+](O)(O)O)[As](=O)(O)O</smiles>

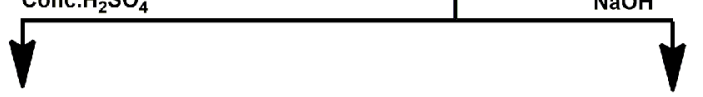<smiles>CC(=O)Nc1cc(C)c(OCc2nnc(S)s2)cc1C(C)C</smiles>

[8]<smiles>CC(=O)Nc1cc(C)c(OCc2nnc(S)o2)cc1C(C)C</smiles>

[9]

Scheme 1: Reaction program.

\section{Antioxidant Activity by DPPH}

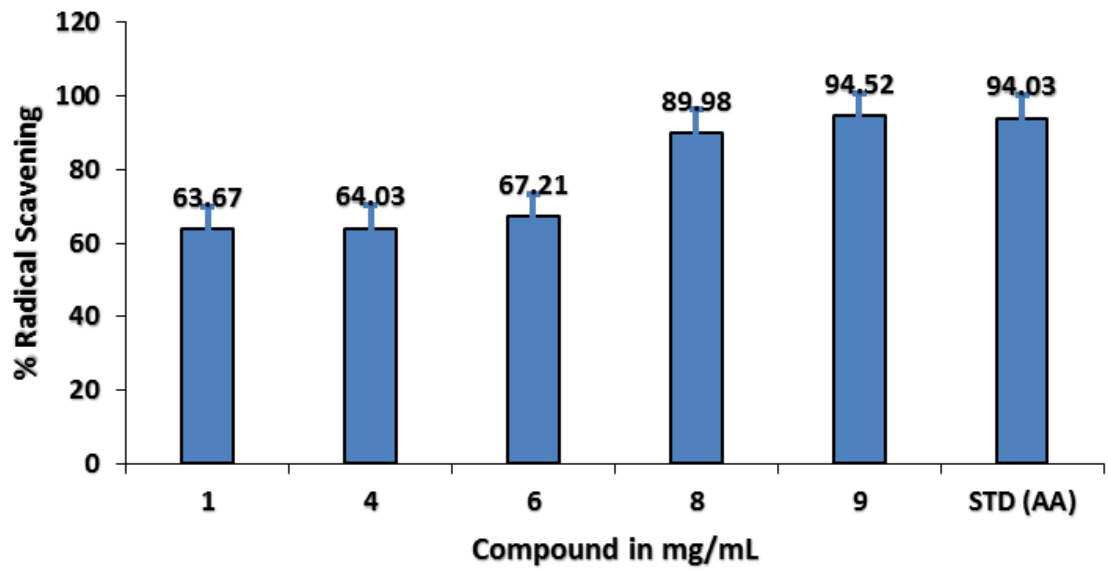

Figure 1: In vitro antioxidant activity of synthesized compounds by using DPPH radical scavenging assay (where Std (AA): ascorbic acid).

General procedure for synthesis of potassium-2-(2-(4acetamido-5-isopropyl-2-methylphenoxy) acetyl) hydrazine carbodithiaoate

The recrystallized product of hydrazide $(0.0035$ moles $)$ in the absolute ethanol $(50 \mathrm{ml})$ was transferred to a conical flask and this reaction mixture was kept in ice bath on magnetic stirrer, care was taken to keep the temperature below $0^{\circ} \mathrm{C}$ for $1 \mathrm{hr}$. To this reaction mixture $\mathrm{KOH}(0.0071$ moles) was added and it was further stirred vigorously for $10 \mathrm{~min}$. Then $\mathrm{CS}_{2}(0.0071$ moles $)$ was added drop by drop after 5-10 min interval. After $1 \mathrm{hr}$. excess amount of $\mathrm{CS}_{2}$ was added and then precipitate formed is nothing but the hydrazine salt. 
Citation: Suresh DB, Jamatsing DR, Pravin SK, Ratnamala SB (2016) Synthesis, Characterization and Antioxidant Activity of Carvacrol Containing Novel Thiadiazole and Oxadiazole Moieties. Mod Chem Appl 4: 193. doi: 10.4172/2329-6798.1000193

Page 3 of 4

The whitish colored salt is filtered off and dried under UV light [30] (Supplementary Figure 7).

General procedure for synthesis of $\mathrm{N}-(2$-isopropyl-4-((5mercapto-1,3,4-thiadiazol-2-yl)-5-methoxy)-5-methylphenyl) acetamide

The dry and pure product of hydrazide salt is taken in the round bottom flask and the cold conc. $\mathrm{H}_{2} \mathrm{SO}_{4}$ at $5^{\circ} \mathrm{C}$ is poured in the round bottom flask. This reaction mixture was stirred on magnetic stirrer at room temperature for about 5-6 hrs. Thereafter the reaction mixture was poured in a beaker containing crushed ice and stirred vigorously for 5-10 min. The pink colored product formed is filtered off and washed with cold water and dried in UV light [30] (Supplementary Figure 8).

General procedure for synthesis of N-(2-isopropyl-4-((5mercapto-1,3,4-oxadiazol-2-yl)-5-methoxy)5-methylphenyl) acetamide

The dry and pure product of hydrazide salt is placed in round bottom flask and $\mathrm{NaOH}$ solution was added into it. This reaction mixture was stirred on magnetic stirrer for about 5-6 hrs. After 5-6 hrs. the stirring was stopped and this reaction mixture was poured in beaker containing crush ice pieces and stirred for 5-10 min. to solidify the product. This product is filtered out and washed with cold water and dried in UV light [30] (Supplementary Figure 9).

\section{Results and Discussion}

\section{In-vitro antioxidant activity}

Antioxidant activity of organic molecules is related to their electron or hydrogen atom donating ability to DPPH radical, so that they become stable diamagnetic scaffolds. The interaction of synthesized compounds with stable DPPH free radical indicates their free radical scavenging ability. The reduction ability of DPPH radicals was determined by decline in their absorbance at $517 \mathrm{~nm}$ enthused by antioxidants [31]. Majority of the tested compounds in these series showed good interaction with the $\mathrm{DPPH}$ radical at $1 \mathrm{mg} / \mathrm{mL}$ concentration. The scavenging effects of all the synthesized compounds on DPPH radical are presented as $\%$ inhibition in (Supplementary Figure 1). DPPH radical scavenging activity of the synthesized compounds exhibited outstanding results as compared to the standard Ascorbic acid. Maximum DPPH radical scavenging activity was observed in compounds (Supplementary Figures 8 and 9) (89.98 and 94.52\%) which is higher or comparable with standard antioxidant ascorbic acid (94.03\%) at the same concentration. It appears that compounds (Supplementary Figures 1, 4 and 6) are also significant scavengers of the DPPH radical with \% inhibition $(63.67 \%$, $64.03 \%, 67.21 \%$ respectively). In Antioxidant results showed that good efficacy and derivatization of the parent compound has resulted in good antioxidant efficacy.

\section{Conclusion}

In conclusion, we have achieved a convenient protocol for the synthesis 1,3,4-thiadiazole and oxadiazole incorporated carvacrol moiety in good yield and evaluated their in vitro antioxidant activity by using DPPH radical scavenger assay. Our antioxidant screening results indicate that exciting DPPH radical scavenging activity was observed in compounds (Supplementary Figures 8 and 9) in comparison with standard ascorbic acid. The lead compounds emerging with the most potent antioxidant activity in this study (Supplementary Figures 8 and 9) will be further structurally modified towards the discovery of a compound with optimal antioxidant activity. These results may also provide some significance guidance for the development of new class antioxidant.

\section{Acknowledgements}

The Authors extend their appreciation to UGC SAP (DSA-I) New Delhi for funding the research work.

\section{References}

1. Dautréaux B, Toledano MB (2007) ROS as signaling molecules mechanisms that generate specificity in ROS homeostasis. Nat Rev Mol Cell Biol 8: 813-824.

2. Ischiropoulos $\mathrm{H}$ (2002) Introduction to serial reviews reactive nitrogen species tyrosine nitration and cell signaling 1,2. Free Radical Biology and Medicine 33: 727 .

3. Butterfield DA, Drake J, Pocernich C, Castegna A (2001) Evidence of oxidative damage in Alzheimer's disease brain: central role for amyloid $\beta$-peptide. Trends in molecular medicine $7: 548-554$

4. Uttara B, Singh AV, Zamboni P, Mahajan RT (2009) Oxidative stress and neurodegenerative diseases: a review of upstream and downstream antioxidant therapeutic options. Current neuropharmacology 7: 65-74.

5. Adly AA (2010) Oxidative stress and disease: an updated review. Res J Immunol 3: 129-145.

6. Miliovsky M, Svinyarov I, Prokopova E, Batovska D (2015) Synthesis and antioxidant activity of polyhydroxylated trans-restricted 2-arylcinnamic acids. Molecules 20: 2555-2575.

7. Vittal S, Poojary B, Bansal P, Nandagokula C (2011) Synthesis, characterization, and antioxidant activity of some 1, 3, 4-oxadiazoles carrying 4-(methylsulfonyl) benzyl moiety. Der Pharma Chemica 3: 138-146.

8. Kotaiah Y, Harikrishna N, Nagaraju, K, Rao CV (2012) Synthesis and antioxidant activity of $1,3,4$-oxadiazole tagged thieno [2, 3-d] pyrimidine derivatives. European Journal of Medicinal Chemistry 58: 340-345.

9. He DH, Zhu YC, Yang ZR, Hu AX (2009) Synthesis and Characterization of Novel Stilbene Derivatives with 1, 3, 4-Oxadiazole Unit. Journal of the Chinese Chemical Society 56: 268-270.

10. Tactics for Management (1986) National Academic Press, Washington DC, p: 157.

11. Adib M, Jahromi AH, Tavoosi N, Mahdavi M, Bijanzadeh HR, et al. (2006) Microwave-assisted efficient, one-pot, three-component synthesis of 3 , 5-disubstituted 1, 2, 4-oxadiazoles under solvent-free conditions. Tetrahedron letters 47: 2965-2967.

12. Swinbourne JF, Hunt HJ, Klinkert G (1987) An Efficient One Pot Synthesis of $4 \mathrm{H}-$ Pyrrolo $[3,2$, ij] quinolines. Advances in Heterocyclic Chemistry 23: 103-170.

13. Pete UD, Zade CM, Bhosale JD, Tupe SG, Chaudhary PM, et al. (2012) Hybrid molecules of carvacrol and benzoyl urea/thiourea with potential applications in agriculture and medicine. Bioorganic \& medicinal chemistry letters 22 : 5550-5554.

14. Kumbhar PP, Dewang PM (2001) Eco-friendly Pest Management Using Monoterpenoids. I. Antifungal Efficacy of Thymol Derivatives. J Sci Ind Res 60: 645-648.

15. Ultee A, Slump RA, Steging G, Smid EJ (2000) Antimicrobial activity of carvacrol toward Bacillus cereus on rice. Journal of Food Protection 63: 620-624.

16. Baser KH, Vashi BS, Mehta DS (1995) Indian J Chem Sect B 34 9: 802-808.

17. Vashi BS, Shah VH (1996) Synthesis and biological screening of substituted thymolyl thiazolidinones and thymolyl azetidinones. Journal of the Indian Chemical Society 73: 491-492.

18. Vashi BS, Mehta DS, Shah VH (1996) synthesis of 2, 5-disubstituted-1, 3, 4-oxadiazole, 1, 5-disubstituted-2-mercapto-1, 3, 4-triazole and 2, 5-disubstituted-1, 3, 4-thiadiazole derivatives as po tential antimicrobial agents. Indian journal of chemistry. Sect. B: Organic chemistry, including medical chemistry $35: 111-115$.

19. Hajimehdipoor, H, Shekarchi M, Khanavi M, Adib N, Amri M, et al. (2010) A validated high performance liquid chromatography method for the analysis of thymol and carvacrol in Thymus vulgaris L. volatile oil. Pharmacognosy magazine 6: 154-158.

20. Bagul SD, Rajput JD, Tadavi SK, Bendre RS (2016) Design synthesis and 
Citation: Suresh DB, Jamatsing DR, Pravin SK, Ratnamala SB (2016) Synthesis, Characterization and Antioxidant Activity of Carvacrol Containing Novel Thiadiazole and Oxadiazole Moieties. Mod Chem Appl 4: 193. doi: 10.4172/2329-6798.1000193

biological activities of novel 5-isopropyl-2-methylphenolhydrazide-based sulfonamide derivatives. Research on Chemical Intermediates, pp: 1-12.

21. Rajput JD, Bagul SD, Tadavi SK, Karandikar PS, Bendre RS (2016) Design, Synthesis, and Biological Evaluation of Novel Class Diindolyl Methanes (DIMs) Derived from Naturally Occurring Phenolic Monoterpenoids. Medicinal chemistry.

22. Quiroga PR, Asensio CM, Nepote V (2015) Antioxidant effects of the monoterpenes carvacrol, thymol and sabinene hydrate on chemical and sensory stability of roasted sunflower seeds. J Sci Food Agric 95: 471-479.

23. Yanishlieva NV, Marinova EM, Gordon MH, Raneva VG (1999) Antioxidant activity and mechanism of action of thymol and carvacrol in two lipid systems. Food Chem 64: 59-66.

24. Burda S, Oleszek W (2001) Antioxidant and antiradical activities of flavonoids. J Agric Food Chem 49: 2774-2779.

25. Vashi BS, Mehta DS, Shah VH (1995) Synthesis and Biological Activity of 4-Thiazolidinones, 2-Azetidinones 4-Imidazolinone Derivatives Having Thymol Moiety. Chem Inform 26.

26. Nargund LVG, Reddy GRN, Hari Prasad V (1996) Synthesis and antibacterial activity of a series 1-aryl-2-mercapto-5-4-acetamidophenoxy) methyl-1, 3, 4-triazoles, thiadiazoles and 2-4-(acetamido-phenox t) carbonyl-3, 4 5 -trisubstituted-pyrazoles. Indian journal of chemistry. Sect. B: Organic chemistry, including medical chemistry $35:$ 499-502.

27. Ellis F, Osborne C (2002) Paracetamol a curriculum resource. Royal Society of Chemistry.

28. Wagle, Adhikari AV, Kumari NS (2008) Synthesis of some new 2-(3-methyl7-substituted-2-oxoquinoxalinyl)-5-(aryl)-1, 3, 4-oxadiazoles as potential nonsteroidal anti-inflammatory and analgesic agents. Indian journal of chemistry. Section B, Organic including medicinal 47: 439.

29. Maslat AO, Abussaud M, Tashtoush H, Talib M (2002) Synthesis, antibacterial, antifungal, and genotoxic activity of bis-1, 3, 4-oxadiazole derivatives. Polish $\mathrm{J}$ Pharmacol 54: 55-60.

30. Aggarwal N, Kumar R, Dureja P, Khurana JM (2012) Synthesis of Nove Nalidixic Acid-Based 1, 3, 4-Thiadiazole and 1, 3,4-Oxadiazole Derivatives as Potent Antibacterial Agents. Chemical biology \& drug design 79: 384-397.

31. Soare JR, Dinis TC, Cunha AP, Almeida L (1997) Antioxidant activities of some extracts of Thymus zygis. Free radical research 26: 469-478. 